tisch mit blosser Empirie, sie verbietet nicht, aus dem Experiment Schlïsse auf das Allgemeine zu ziehen und sie hat zur Theorie von der Unzerstörbarkeit der Kraft und damit zur Abstraction der mechanischen Weltanschauung geführt.

Da eine einfache Thatsache finden und registriren leichter ist, als durch längeres Nachdenken einer Erscheinung auf den Grund zu gehen, so ist das Sichbegnïgen mit dem Sammeln von Thatsachen unendlich viel populärer, als die Aufstellung von aus gesammelten Thatsachen gefolgerten Ideen. Letztere werden oft genug von den Enthasiasten der blanken Empirie als "Speculation" verdammt, nur weil ihnen zuwider ist, tiefer in eine Sache einzudringen.

\title{
Bemerkungen über die Constitution des Albumins.
}

Von

\section{I 0 w.}

Unter den Erörterungen Baumanns befinden sich auch einige Bemerkungen über die Präexistenz des Leucin- und Tyrosincomplexes im Eiweissmolecul, welche ich einer speciellen Betrachtung unterwerfen will. Meine Ansicht ist, dass diese Complexe nicht fertig gebildet sind, sondern bei der Eiweisszersetzung leicht unter Wasserspaltung und (der Benzolkern des Tyrosins) unter Bindungsänderungen zu Stande kommen. Ich fand es für physiologisch höchst unwahrscheinlich, dass die Zellen zuerst einen Benzolkern, dann einen hydroxylirten Benzolkern, hierauf das Leucin und die Amidoglutarsäure sich bereiten, und mit den noch weiter nöthigen Stickstoffmengen und dem Asparaginsäurecomplex alle diese Gruppen in Form eines complicirten Harnstoffs oder Guanidins zusammenfügen sollten. Es schien doch viel natürlicher, dass bei der Raschheit, mit welcher sich das Eiweiss bildet und vermehrt, ein einfach verlaufender $\mathrm{C} o$ ndensationsprozess, - wie bei der Bildung der Glycose aus Formaldehyd, - der Eiweissbildung zu Grunde liege. 
Einerseits die Ergebnisse der Studien Nägeli's über die Ernährung der niedern Pilze, andererseits die Arbeiten von Pfeffer, Schulze und Barbieri, Borodin etc. über die höchst merkwürdige Rolle des Asparagins beim Eiweissumsatz in den Pflanzen führten mich zum Schlnss, dass das Eiweiss (resp. Pepton) ein Condensationsproduct des Asparaginsäurealdehydes sei und dass dieser ans Formaldehyd und Ammoniak entstehe ${ }^{1}$ ). Der Aldehyd der Asparaginsäure ist freilich noch ein hypothetischer Körper und Nencki konnte vor mehreren Monaten noch mft Recht sagen, Aldehyde von Amidosäuren müssten so labile Körper sein, dass man die Möglichkeit der Darstellung bezweifeln müsse (Journ. f. pr. Chem. Sept. 1882). Indess haben vor Kurzem Gabriel sowohl, als Friedländer den ersten Aldehyd einer Amidos äure im freien Zustande dargestellt, den Aldehyd der Orthoamidobenzoesäure ${ }^{2}$ ). Derselbe lagert sich allerdings unter manchen Umständen sehr leicht um unter Verlust der Aldehydgruppirung.

Früher herrschte bekanntlich die Ansicht Liebigs allgemein, dass aus der Kohlensäure bei der Pflanzenassimilation zuerst Oxalsäure und hieraus durch einen fortschreitenden Reductionsvorgang zuletzt der Zucker werde. Seit 1870 hat aber diese Ansicht wohl kaum einen Vertreter mehr. A. Baeyer und Kekulé haben eine ungleich einfachere Theorie aufgestellt, die jetzt allgemein acceptirt ist, nach welcher die Glycose durch Condensation des Formaldehyds entsteht. Noch Niemanden ist der experimentelle Nachweis hiefür gelungen - aber logische Schlüsse haben zum Glück Berechtigung in der Wissenschaft, - auch wenn das Experiment noch nicht sein entscheidendes Wort gesprochen hat.

Was meine Ansicht, dass der Lencincomplex nicht fertig gebildet im Eiweissmolecul enthalten ist, betrifft, so halte ich an der Beweiskraft des Verhaltens der Ueberosmiumsäure fest. Jeder Körper, der die Gruppe $\mathrm{CH}_{3}-\mathrm{CH}_{2}-$ enthält, reducirt eine verdünnte Ueberosmiumsäu relösung und die Leichtigkeit der Reduction nimmt mit dem Eintritt jedes weiteren $\mathrm{CH}_{2}$-Gliedes zu. Der Einwurf Baumann's, dass gewisse

1) Hierüber Dieses Archiv, Bd. XXII, p. 251. Ausführlicher in unserer oben erwähnten Schrift.

2) Ber. d. chem. Gesellsch. XV. p. 2004 and 2572. 
Atomcomplexe in verschiedenen Verbindungen sich reducirenden Mitteln gegenuiber verschieden verhalten können, wie das.Verhalten der alkalischen Kupferlösung gegen Glycose einerseits, gegen Rohrzucker andererseits beweise, hat hier keine Bedeutung. Möge Baumann erst beweisen, dass die Ueberosmiumsäure auch Ausnabmen macht; vom Kupferoxyd Parallelen auf die Ueberosmiumsäure zu ziehen, muss als unstatthaft erklärt werden.

Wir wollen nun die Frage, ob der Benzolkern fertig gebildet im Eiweissmolecul vorhanden sei, etwas näher betrachten. Baumann nimmt nicht nur einen, sondern $z$ wei Benzolkerne im Eiweiss an, einen hydroxylirten und einen nicht hydroxylirten; ersterer trete im Tryosincomplex aus, letztrer käme bei Oxydationen des Albumins als Benzaldehyd oder Benzoesäure zum Vorschein. Meiner Ansicht nach können sich aus dem Eiweiss- (resp. Pepton-) Complex zwar zwei Benzolkerne durch Aenderuag der Bindungsverbältnisse leicht bilden, aber sie sind nicht fertig: gebildet. Bei Zersetzung des Eiweisses mit starken Säuren kommt nur die Bildung eines einzigen, des hydroxylirten zu Stande, der dann in Form von Tryosin austritt. Nur bei geeigneten Oxydationen wird auch der zweite Ring gebildet, der dann als Benzoesäure oder Benzaldehyd wahrnehmbar wird.

Die Gründe, welche Baumann für die Präexistenz des hydroxylirten Benzolkerns in's Feld führt, sind:

1) Aus Eiweiss kann durch lösliche Fermente Tyrosin abgespalten werden; bei der Wirkung löslicher Fermente habe man aber noch nie Atomwanderungen oder Sprengung von Kohlenstoffketten beobachtet. - Das scheint auf den ersten Blick als ein ganz entscheidender Punct. Wie Kühne beobachtete hat das Trypsin (bei anderen Fermenten hat man eine solche Wirkung meines Wissens nicht nachweisen können ${ }^{1}$ ) die Fähigkeit, das Eiweiss zu spalten, wobei Tyrosin und Leucin auftreten; gleichzeitig entsteht dabei Antipepton, welches von Trypsin, nach K $\mathfrak{u} h \mathbf{n e}$,

1) In anderen Fällen, in denen man den Zerfall des Eiweises, resp. Peptons behauptete, mögen die Bacterien übersehen worden sein. Schon öfters wurde eine Wirkung ungeformten Fermenten zugeschrieben, die lediglich auf Bacterienthätigkeit beruhte, z. B. die Bildung des Coniferylalkohols aus Coniferin. F. Tiemann glaubte hier die Wirlung des angewandten Emulsins vor sich zu haben, während, wie ich fand, lediglich Bacterien jene Umwandlung herbeiführten. 
nicht angegriffen wird. Wenn also jener Schluss berechtigt sein soll, so dürfte auch der berechtigt sein, dass im Antipepton der Tyrosincomplex nicht vorhanden ist. Auch die auffallende Beständigkeit des Eiweisscomplexes in Berührung mit concentrirter Schwefel- oder Salzsäure bei gewöhnlicher Temperatur spricht gegen Baumanns Ansicht. Man kann Eiweiss dem anderthalbfachen bis doppelten Gewichte dieser Säuren monatelang bei gewöhnlicher Temperatur stehen lassen, ohne dass die Veränderung weiter ginge als bis zur Peptonisirung. Bei Erhöhung der Temperatur findet freilich eine rasche Spaltung statt. - Wäre das Eiweiss (resp. Pepton) ein complexer Harnstoff nach Sch ützenberger, oder ein complexes Guanidin nach Baumann, so müsste bei einer mit so einem gelinden Mittel wie Trypsin herbeigeführten Eiweissspaltung entschieden Harnstoff auftreten. Noch Niemand hat aber diesen oder irgend eine andere Atomgruppirung nachgewiesen, welche die aus dem Eiweis erhaltbaren Amidosäuren zusammenhalten soll!1). Die Thatsache, dass Eiweiss bei Spaltung mit Barythydrat auch Kohlensäure and Ammoniak liefert, ist für die Harnstoffgruppirung nicht beweisend, weil jene Körper auch aus ganz rerschiedenen Theilen des grossen Eiweissmoleculs stammen können.

2) Eiweiss gibt direct die Millon'sche Reaction, welche bekanntlich für monohydroxylirte Benzolderivate charakteristisch ist. Nun ist aber hier zu bedenken, dass bei diesem Vorgang die stark saure Mischung stets gekocht werden muss und dass unter solchen Verhältnissen oft sehr leicht Bindungsänderungen eintreten. Der Benzolkern bildet sich in manchen Fällen äusserst leicht; so gibt.Crotonylen beim Schütteln mit Schwefelsäure (3 Theile Säure, 1 Theil Wasser sehr raseh und schon bei gewöhnlicher Temperatur Hexamethylbenzol (Almedingen).

Da Tyrosin nicht nur durch Permanganat, sondern auch durch Chromsäure eine sehr weitgehende Oxydation erfährt, wobei sein Benzolkern wegen des darin vorhandenen Hydroxyls angegriffen und zerstört wird, so kann man allerdings nicht erwarten, dass eine aromatische Hydroxysäure bei Oxydation des Eiweisses auch dann erhalten würde, wenn der Tyrosincomplex fertig darin vorhanden wäre.

1) Die von Lossen bei Eiweissoxydation erhaltene Guanidinmenge ist ja viel zu gering, als dass sie hier ernstlich in Betracht kommen könnte. 
Was nun Baumann's weitere Behauptung anlangt, dass auch ein nichthydroxylirter Benzolkern im Eiweisseomplex vorhanden sei, weil bei manchen Oxydationen Benzoesäure erhalten werde, so sind auch hier die Oxydationen mit chromsaurem Kali und Schwefelsäure oder mit Braunstein und Schwefelsäure nicht beweisend aus schon angeführten Gründen ${ }^{1}$ ). Nur solche Oxydationen, welche bei gewöhnlicher Temperatur und mit möglichst neutral reagirenden Medien ausgeführt wurden, können als beweiskräftig betrachtet werden. Hieher gehört aber die Oxydation mit Permanganat, welche zum Zwecke des Nachweises der Harnstoffbildung aus Eiweiss ja schon zu wiederholten Malen ausgeführt wurde.

Nun gab zuerst Städeler an, dass man bei dieser Oxydation kleine Mengen Benzoesäure erhalte. Nach ihm führte Subbotin ${ }^{2}$ ) diese Oxydation aus und er erhielt nahezu 1,5\% Benzoesäure, welche er durch Schmelzpunct und Baryumbestimmung im Barytsalz identificirte. Wie verhält sich aber hiezu das Resultat von Lossen ${ }^{3}$ ) und von Pott $^{4}$ )? Lossen führte die Oxydation mit sebr grossen Mengen, einmal sogar mit $1000 \mathrm{gr}$ Albumin aus und erwähnt nur Spuren ("etwas") Benzoesäure, Pott unternahm eine grosse Versuchsreihe mit Conglutin und untersuchte besonders die flüchtigen Säuren, welche bei dessen Oxydation mit Permanganat entstehen - und fand wohl Buttersäure - aber von Benzoesäure sagt er nichts, die ihm doch gewiss nicht hätte entgehen können; nur einmal erwähnt er einen deutlichen Geruch nach Bittermandelöl. Wäre ein nicht hydroxylirter Benzolkern im Eiweiss enthalten, so müssten bei vorsichtiger Oxydation mit Permanganat in der Kälte 6-7\% Benzoesäure aus dem Eiweiss erhalten werden. Warum hat aber Subbotin 1,5\% Benzoesäure erhalten, Lossen und Pott nur Spuren oder nichts? Subbotin und Städeler erwärmten das Oxydationsgemisch auf $50-60^{\circ}$ und neutralisirten von Zeit zu Zeit. Lossen aber setzte dem Kaliumpermanganat

1) Die von Schulze and Barbieri in den Lupinenkeimlingen aufgefundene Phenylamidopropsinsäure kann ebensowenig als Beweis hier angeführt werden; sie kann ein Reductionsproduct des in kleiner Menge in Keimlingen öfters auftretenden Tyrosins sein.

2) Chem. Centralblatt 1865, p. 595.

3) Liebig's Ann. 201. 369.

4) Journ. f. prakt. Chem. [2.] 5. p. 355 und 6. p. 91 . 
Magnesiasulfat $\mathrm{zu}$, um eine möglichst neutrale Reaction zu haben und liess den Process bei gewöhnlicher Temperatur verlaufen. Pott hat bei seinen zahlreichen Oxydationsversuchen nur einmal eine höhere Temperatur angewandt und liess die Mengen des Permanganats zwischen sehr weiten Grenzen variiren.

Da benzoesaure Salze bei gewöhnlicher Temperatur nicht, wohl aber bei höherer von Permanganat allmählich angegriffen werden, so hätten sowohl Lossen als Pott noch viel grössere Mengen Benzoesäure erhalten müssen als Subbotin.

Auch die Bromirungsversuche von Hlasiwetz können keinen Beleg für Baumann's Ansicht liefern, da bei dem eingeschlagenen Verfahren die Wirkung der gebildeten Bromwasserstoffsäure nicht ausgeschlossen wurde.

Die Anwesenheit eines nicht hydroxylirten Benzolkerns im Eiweiss ist auch schon deshalb ganz unwahrscheinlich, weil die Menge der aromatisehen Substanzen in Harne dann bedeutend grösser sein müsste als man gefunden hat.

Ich kann demnach Baumann's Schlussfolgerungen keineswegs als beweisende anerkennen. 